INFORMAL LOGIC XI.1, Winter 1989

\title{
The Human Image System and Thinking Critically in the Strong Sense ${ }^{1}$
}

\author{
JAMES B. FREEMAN Hunter College-CUNY
}

The purpose of this paper is to see whether the concept of the image system throws light on the enterprise of thinking critically in the strong sense. To do this, we shall first sketch what strong sense critical thinking involves, according to its major proponents. We shall then examine the concept of the image system together with its growth and dynamics. This will prepare us to deal explicitly with our principal task-developing the connections between the image system and strong sense critical thinking. We shall conclude with certain practical and philosophical considerations, in particular considerations on teaching people to be strong sense critical thinkers.

\section{Critical Thinking in the Strong Sense}

What is perhaps common to a number of authors who have concerned themselves with the general area of strong sense critical thinking is the view that critical thinking is not simply a skill or technique, but concerns dispositions and the affective side of a person. For example, in "Goals for a Critical Thinking/Reasoning Curriculum,", Robert $H$. Ennis lists a number of dispositions including seeking reasons, trying to be well informed, taking into account the total situation, being openminded-respecting other points of view, reasoning as cogently as possible from premises one does not accept, withholding judgement when evidence is insufficient, allowing the weight of evidence to determine one's position. ${ }^{2}$ Similarly, in "Educating Reason: Critical Thinking,
Informal Logic, and the Philosophy of Education," Harvey Siegel defines a critical thinker as "one who is appropriately moved by reasons: she has a propensity or disposition to believe and act in accordance with reasons; and she has the ability to assess the force of reasons in the many contexts in which reasons play a role. ' 3 Besides the skill to properly assess reasons, then, critical thinking involves "the willingness, desire, and disposition to base one's actions and beliefs on reasons, that is, to do reason assessment and to be guided by the results of such assessment... the critical attitude or critical spirit component of critical thinking." 4 A critical thinker values, nay has a passion for, clear thinking and good reasoning. 5

The expression " critical thinking in the strong sense"' is most typically associated with the name of Richard Paul. ${ }^{6}$ Paul offers a distinctly richer conception of strong sense critical thinking than either Ennis or Siegel. For Paul, learning to be a critical thinker is not a matter of simply acquiring certain habits and dispositions, like learning to hit a tennis ball properly. It is not simply a matter of acquiring certain loves, as one might acquire a love of Shakespearean poetry. Someone who has no disposition one way or the other, to play tennis well or badly, may acquire by dint of effort a disposition to play effectively. Likewise, a person with no feelings one way or the other about Shakespeare may, by proper refinement of taste, acquire a love of Shakespearean poetry. In both models, someone who was neutral acquires a positive disposition or affect. But for Paul, 
a person "naturally", has certain blocks or resistances against thinking critically. We have egocentric and sociocentric tendencies, habits of thought which impede critical thinking. These result in our holding prejudices and stereotypes, in our suffering from blind spots, in our having tendencies to self-deception. No one may be able to escape from these completely. Being a critical thinker may be a matter of degreewe cannot separate persons into critical thinkers and non-critical thinkers. But the project of growing as a critical thinker involves outgrowing these blocks to critical thinking.

Whence come these blocks? Humans are engaged in life projects which define them as persons, which give them an identity. A particular individual's life project affects and determines, in a unique way, how that individual interprets and conceptualizes his world, what he values in it. It gives him interests-better vested interests, stakes, and perceptions. ${ }^{7}$ It gives him, in short, a point of view, a world view in fact. Human beings are furthermore social creatures, and society-centrally contemporary societyexerts a profound affect on one's world view. In particular, it furnishes ready made a system of categories for interpreting one's experience which is simply accepted uncritically. Paul sees the problem going deeper than merely accepting this material without critical scrutiny:

My view is that people as they are now largely constituted... are deeply irrational, acting habitually on the basis of first principles, concepts and assumptions, to which they have not given, and could not give, free, conscious, and deliberate assent... They lack skills of primary categorization, little sense of what it would be to question the basic labels and categories on the basis of which they multiply inferences of divergent logical types... They have no conscious congnizance of what it would be to decide for themselves on the basis of rational reasons which fundamental labels ought to be attached in a primary, inferencedetermining way to which situations, persons, and events. ${ }^{8}$
Taking the frameworks which our individual life projects and our cultural backgrounds give us as real, committing ourselves to them to such a degree, even if unconscious, Paul regards as an expression of egocentricity or sociocentricity.

For Paul, becoming a critical thinker means developing the ability to transcend one's point of view. A critical thinker sees an issue not only from his own viewpoint, but can entertain the viewpoints of others, discerning what is true or of value in them, and modifying his claims and reasoning accordingly. For example, by recognizing how an argument is connected with advancing an interest, "we can, by imaginatively entertaining a competing interest, construct an opposing point of view and so an opposing argument or set of arguments. It is by developing both arguments dialectically that we come to recognize their strengths and weaknesses." 9 This attempting to enter another's point of view, to think dialectically or dialogically about an issue, is the key to becoming a critical thinker as Paul sees it.

Clearly, there is much room for further articulating a view which sees critical thinking as inherently involving the project of transcending our egocentric and sociocentric biases through dialectically entertaining and reasoning from the points of view or world view of others. What does egocentricity and sociocentricity mean? How are they manifested? What is a point of view or world view, and what exactly does dialogical, multi-point-of-viewed thinking involve? Whatever can shed light on these issues will deepen our understanding of strong sense critical thinking, as Paul has protrayed it. Furthermore, in presenting this conception of critical thinking, Paul makes certain claims which are definitely open to challenge: Are human beings "naturally", egocentric? Do they tend toward egocentricity or sociocentricity? Do self and society foster a set of categories by which we impose an interpretation on the world? That is, do self and society both give us interpretive categories which it is a mistake to count as "reality"? 
Paul's emphasis on dialectical thinking as the way to transcend native egocentricity and sociocentricity also raises another question: Is this the only way to transcend this condition in the direction of critical thinking? Could one, by gaining insight into the dynamics of one's egocentricity and sociocentricity, be liberated from their retardant effects on one's critical thinking? As psychoanalysis aims to free a patient from the constricting effects of some neurosis by insight into the dynamics of his neurotic conflict, may we be freed from our egocentricity by insight into its operation? Or is this just one mode of dialogical thinking - albeit a mode deserving special emphasis and attention?

We cannot address all these questions within the scope of this paper. In particular, we cannot develop the notion of dialectical or dialogical thinking here. ${ }^{10}$ Rather, we shall focus in this paper on the notions of world view, point of view, egocentricity, and sociocentricity. It is our contention that the concept of the image system, as developed by several authors especially interested in human communication, can shed valuable light on these notions and their interrelations. In particular, these concepts should help us answer a number of the critical questions we have outlined above. But what is an image? What is meant by the image system?

\section{The Human Image System: Its Nature}

As the name of Richard Paul is intimately connected with the concept of critical thinking in the strong sense, so several names are connected with the notion of the image or image system. Kenneth E. Boulding presented the concept in The Image: Knowledge in Life and Society. ${ }^{11}$ Clevenger and Sproule have amplified the view. ${ }^{12}$ All three of these authors specifically use the term "image" to indicate the concept they are developing. Walter Lippmann in Public Opinion ${ }^{13}$ speaks rather of stereotypes. However Lippmann's views on stereotypes provide valuable insights into the nature of the image system.

Boulding begins by distinguishing various types of images which may enter into a person's image system. First, there is the spatial image. Each person pictures himself in some spatial location. Not only does he see certain objects in front of him and know he should see others if he looked in the proper direction, but he has a picture of what he considers lies geographically beyond his immediate purview. This picture involves not just specific geographical features-mountains begin beyond the outskirts of the city - but global, even cosmic features. At one time, many humans pictured the world as one flat level in a threestoreyed universe. Contemporary westerners picture it as round in an open universe of galaxies. Beside the spatial image is the temporal image. We can picture our personal past and project events in our future. The temporal image also includes global aspects. Is time cyclical or linear?

By virtue of kinship and friendship ties, the social roles I play, and the offices I fill, I am related to other human beings and can picture what this means in terms of the reactions of others to me. A teacher, by virtue of her role, expects certain behavior from her students. That is part of her image of herself as teacher. All these are elements in the image of personal relationship. In addition to personal relationships, we have an image of mechanical or mechanistic relations. Our picture of the world is of one which displays causal regularities, conditional dependencies, relatively constant sequences of occurrences, and which may be influenced or manipulated in various ways. "If I do A, B will occur."

All of these images concern self and world. They go to building up a picture of my world and my place in it. It is also part of that picture that I react affectively to the world, that I experience different emotional reactions to different objects at different times. In addition, I have an image of the value of the various objects in my world, 
an "ordering on the scale of better or worse of the various parts of the whole image." 14 Finally, our image system contains a picture of what is real and what is unreal. For many, the physical objects we see and touch are regarded as real; what we dream or imagine is not. ${ }^{15}$

Implicit, perhaps, in Boulding's discussion, but brought out more clearly by Clevenger, is that our image system includes images of the particular objects in space and events in time into which our experience is organized. We do not simply experience sense impressions, but rather we have experiences of objects in our world.

When we say that experience is organized, we mean that separate stimuli are linked to other stimuli, past and present, in such a fashion that the occurrence of one leads us to infer or predict the occurrence of others... For each of us experiences become organized around certain foci. That is, the innumerable stimuli to which we are subjected are not randomly connected with one another but are clustered around a much smaller number of central nodes. ${ }^{16}$

This clustering includes not only what may pertain to some object proper, but the various associations related to or connected with it. Clevenger's example is "The Automobile." Not only does this node include the ability to identify automobiles when we see them and differentiate various types, but also such related associations as traffic officer, car pool, and death on the highways. ${ }^{17}$ We may, then, distinguish not only the spatial, temporal, relational images, but the images of particular objects within space and time. As Clevenger defines it, "the image of a thing is the complex of associations that it arouses within an individual." 18 As Sproule makes explicit, these associations may include not only specific beliefs about an object, but attitudes toward it as well. ${ }^{19}$

What may we say, then, is the image system according to these conceptions we have been examining? Although it may be unfair to say that the very categoreal scheme of space, time, relation is proper to the image system, certainly what is pictured to fill in that framework is. The image system gives us an organized world, with organized particular objects, related in various ways and dimensions. The image system is our system of images of what the spatial, temporal, relational dimensions of the world are like, which objects and events are related in those dimensions, and what value different elements of the world have for us.

Lippmann's discussion of stereotypes in Public Opinion adds further detail to this image of the image system. Our images of countries may include pictures of their embodying certain moral qualities and values, besides images of their geographical details. Wartime propaganda may especially cultivate this aspect of national images. Besides images of personal relations, we have images of persons in relation. "Great men, even during their lifetime, are usually known to the public only through a fictitious personality." ${ }^{20}$ Not only great heroes but notorious villains may be imaged.

If everything good was to come from Joffre, Foch, Wilson, or Roosevelt, everything evil originated in the Kaiser Wilhelm, Lenin and Trotsky. They were as omnipotent for evil as the heroes were omnipotent for good. To many simple and frightened minds there was no political reverse, no strike, no obstruction, no mysterious death or mysterious conflagration anywhere in the world of which the causes did not wind back to these personal sources of evil. ${ }^{21}$

Here we have a striking example of what may be a component in someone's personal relation image.

Lippmann furthermore makes some striking comments on how our images or stereotypes are bound up with perception and import meaning into what we experience.

For the most part we do not first see, and then define, we define first and then see. In the great blooming, buzzing confusion of the outer world we pick out what our culture has already defined for us, and we tend to perceive that which we have picked out in the form stereotyped for us by our culture. ${ }^{22}$ 
What does this mean? On Lippmann's view, when we perceive something we experience some sign, and then fill out our perception with preconceived images of what that sign signifies.

The signs stand for ideas, and these ideas we fill out with our stock of images. We do not so much see this man or that sunset; rather we notice that the thing is man or sunset, and then see chiefly what our mind is already full of on those subjects... We notice a trait which marks a well known type, and fill in the rest of the picture by means of the stereotypes we carry about in our heads. ${ }^{23}$

So, on Lippman's view, much of what we perceive we actually bring with us to the perceptual situation. Many of the features, factors, properties we might ascribe to an object perceived are elements in our image of the object rather than attributes actually seen.

Stereotypes provide principles for interpreting far more than what we experience first hand. We get much information, many reports about affairs beyond our immediate purview. But our picture of what is going on is determined largely by our stereotypes.

Of the great men who assembled at Paris to settle the affairs of mankind, how many were there who were able to see much of the Europe about them, rather than their commitments about Europe? Could anyone have penetrated the mind of $\mathrm{M}$. Clemenceau, would he have found there images of the Europe of 1919, or a great sediment of stereotyped ideas accumulated and hardened in a long and pugnacious existence? Did he see the Germans of 1919, or the German type as he had learned to see it since 1871 ? He saw the type. ${ }^{24}$

What has this brief review of Lippmann's views added to our conception of the image system? Besides giving greater detail, this consideration has underscored how the image system has a dynamic of its own. It is not merely a reflection of the external world, but a principal determinant of our world, especially as a system of meaningful elements or elements which bear meaning. Our images give us the world we inhabit.

Whence comes the image system? In Public Opinion, Lippman emphasizes that the image system is a pseudo-environment inserted between a person and his or her actual environment. How did that environment come to be there? From what sources did it arise and what forces maintain it? These questions are central to comprehending why the concept of the image system is important for understanding and developing the enterprise of critical thinking in the strong sense. They concern the sources and dynamics of the image system, which we discuss in the next section.

\section{The Human Image System: Its Sources and Dynamics}

How does the image system develop and evolve? What forces foster its growth? This is an important question, and one which has a distinct import for critical thinking. We may identify three sources which feed the human image system. The first is the experience of each individual. What we experience of particular objects, persons, places gives us raw material for their images. My image of San Francisco is due, at least in part, to the experiences I have had there. If two visitors had very similar experiences of San Francisco, arriving and departing together, visiting the same places, seeing the same sights, we should expect their images to be quite similar. If their experiences were different, their images of San Francisco might also be different. This has lead Sproule to claim that each person's image of something is unique to that person. Although two person's images of an object may converge to a great extent, they most likely will not be identical. ${ }^{25}$ This fact is also behind Boulding's calling our image of something the totality of our subjective knowledge of it. ${ }^{26}$

Our experience of something need not be direct to contribute to our image of that thing. 
None of us has seen George Washington. But we all have an image of the man-based on what we were told in school, the legends we have heard, the pictures we have seen and the associations they evoke. Likewise few of us have seen Antarctica. Yet we all have images of that continent based on various reports-verbal and pictorial. Reports, stories, pictures, all such secondhand information may contribute to the image system.

The mention of George Washington brings us to the second main source of images-society itself. For many Americans' image of George Washington is not simply the image of an historical figure but of an epic personage. Society has transmitted that aspect of the image. Boulding speaks of the public image.

The basic bond of any society, culture, subculture, or organization is a "public image," that is, an image the essential characteristics of which are shared by the individuals participating in the group... An enormous part of the activity of each society is concerned with the transmission and protection of its public image; that set of images regarding space, time, relation, evaluation, etc., which is shared by the mass of its people. ${ }^{27}$

But over against these two sourcesexperience and society - which are basically external to the individual, there is another factor in the development of the image system-an individual's own needs, desires, motivations, affects. Two needs are principal here. As we have noted, our image system gives meaning to our experience. This function of the image system answers to a distinct subjective human need or motivation. Humans want to make meaning of their world. As Daniel Katz points out in "The Functional Approach to the Study of Attitudes," desire for knowledge in the sense of organizing principles, principles which, in John Dewey's words, will introduce definiteness and distinction and consistency and stability of meaning, is a distinct human motivation. People want explanations and our images provide them.
They want an adequately structured, meaningful, organized, clear and consistent universe, and our stereotypes give them what they want. ${ }^{28}$ Thus, something may become part of our image based on our subjective need to have an explanation, to know what something means. This need for meaning may be itself fed by deep urges. The threat of meaninglessness is one of the existential threats to the self. What gives meaning may be accepted to allay this basic anxiety. Not just a positive interest in meaning, but this basic anxiety may drive us to seek explanations and form images and stereotypes.

But speaking of a threat to the self leads directly to a second subjective need the image system may serve-the ego-defensive need. There are more threats to the ego than existential anxieties. We may need to hide from our inner conflicts, unacceptable impulses, and external threats in general, and to avoid the anxiety these factors arouse. We need to save our egos or self-images, and our image system may serve this function. Typical here are attitudes of superiority towards some minority group. They may stem from our own feelings of inferiority and the threat these feelings pose to our ego. By seeing some group as inferior to us, we assuage our feelings of inferiority. These attitudes, then, are ego-defensive and their inclusion, strength, and position in the image system indicates its ego-defensive function. In Public Opinion, Lippman points out how stereotypes can serve both these functions:

\footnotetext{
A pattern of stereotypes is not neutral. It is not merely a way of substituting order for the great blooming, buzzing confusion of reality. It is not merely a short cut. It is all these things and something more. It is the guarantee of our self-respect; it is the projection upon the world of our own sense of our own value, our own position and our own rights. The stereotypes are, therefore, highly charged with the feelings that are attached to them. They are the fortress of our tradition, and behind its defenses we can continue to feel ourselves safe in the position we occupy. ${ }^{29}$
} 
That the image system serves the knowledge and ego-defensive needs is central to understanding its dynamics. What do we mean by dynamics? Our image systems exert a profound affect on how incoming messages affect each of us. All of the authors we have been examining emphasize this point. A incoming message is not simply received by a listener. Incoming information may not produce belief. A message intended to change attitudes may not have that effect. The message must interact with the listener's image system and its overall effect will be determined not just by its content but by that image system. By the dynamics of the image system we mean the forces it brings to play in this interaction. What are these forces? As Clevenger points out, "Images affect response to incoming messages in three ways: They influence attention, interpretation, and acceptance." 30 The images in a person's image system maybe ordered on a salient-latent scale. Salient images are those which are aroused, brought to consciousness, quite easily, while those which are latent may come to consciousness only with much stimulation. One will pay far more attention to a message concerned with an image salient in his or her image system than to one which is latent. We should note that not only are particular images salient or latent as a whole, their various components or elements are salient or latent in different degrees in different image systems. Not only will messages dealing with the salient features of an image gain more attention than those dealing with latent features, this saliency or latency of the elements also affects how messages are interpreted. What we think someone is saying is influenced heavily by the saliency of the elements in the images his or her message arouses. The message that Hemingway enjoyed bullfights may be interpreted quite differently, depending on what elements of the image of bullfighting-blood and death or the matador's skill and the bull's courage-are salient in an auditor. ${ }^{31}$
But the most important effect, from the point of view of critical thinking, that our image system has on incoming messages is its affect on whether they are accepted. One striking feature of the image system is its conservatism-it is resistant to change through experience. It seeks to preserve itself. This means we tend to reject messages which are at variance with our image system, and accept those in harmony with it. Messages which confirm, strengthen, or enhance our already existing images will be accepted. Those which threaten the image system will be actively rejected and resisted.

The image system fosters various kinds of selectivity to let us ignore threatening messages. Some we may avoid altogether. If they are contained or developed in a newspaper story, we just don't read the story. If we do read it, we promptly forget the whole article, or pay attention just to those messages that confirm our image. If we do pay attention to the imcompatible messages, we may interpret them so as to confirm our image. For example, suppose we picture Muammar Qaddafi as a mad dog, as President Reagan once described him. Suppose we hear that Qaddafi is a man of compassion-genuinely aggrieved at human suffering, visiting hospitals to comfort the sick and wounded, their sight leaving him deeply troubled. Instead of rejecting this message, we might reinterpret it by asking-Are these crocodile tears? Is this the master stroke of propaganda-looking compassionate while underneath plotting terror just for the sake of human suffering? Again this renders us immune to the force of the message as evidence of Qaddafi's character. ${ }^{32}$

Lippmann has a very nice illustration of selectivity caused by the American stereotype of progress. This stereotype was framed in terms of physical expansion or development. Whatever had grown, gotten bigger, developed was an instance of progress. And progress surely is good. This stereotype let Americans see all the advan- 
tages but none of the disadvantages of how their society was evolving.

They saw the expansion of cities, but not the accretion of slums; they cheered the census statistics, but refused to consider overcrowding; they pointed with pride to their growth, but would not see the drift from the land, or the unassimilated immigration. They expanded industry furiously at reckless cost to their natural resources; they built up gigantic corporations without arranging for industrial relations. They grew to be one of the most powerful nations on earth without preparing their institutions or their minds for the ending of their isolation. ${ }^{33}$

To use a good psychological term, a stereotype sets us to see what confirms the stereotype and to overlook what conflicts with it. This dynamic of the image system is a direct consequence of its serving the meaning and ego-defensive functions. Disturbing an image risks attacking the meaning fabric of our world and our placeincluding what we may picture to be our privileged place-in it. As Lippmann puts it, to disturb the stereotypes is to attack the foundations of the world, our world at least. ${ }^{34}$

Of course, not all discordant messages will be rejected. The image system can be weakened and ultimately modified by new information. Repeated messages at variance with an image may introduce tension into the image. Our picture will no longer be consistent. Once there are tensions in the image, then it may be far more open to modification. ${ }^{35}$ Enough tension producing messages and we may significantly revise the image. But for the purpose of understanding the implications of the image system for critical thinking in the strong sense, the effect of images on messages, the fact that the image system has a great effect on how we accept the messages we receive is paramount. We shall develop the implications of this dynamic in the next section.

\section{Implications for Strong Sense Critical Thinking}

In section one we posed a number of questions concerning strong sense critical thinking. What is a point of view or world view? Do humans impose categories of interpretation on their world or their experience which are creations, artifacts, and which should not be regarded as "real'? What do egocentricity and sociocentricity involve? Are humans naturally egocentric or sociocentric? If human beings are egocentric and sociocentric, can this condition be transcended by analyzing the egocentricity and sociocentricity? It should be clear at this point that our consideration of the human image system in the last two sections has provided much material for answering these questions. Reflections on the image system provide evidence for and insights into a "natural" human condition which is inimical to strong sense critical thinking. They also suggest ways in which we may grow as critical thinkers. In this section we want to develop answers to the questions we have posed, and make plain these implications of the human image system.

What is a person's world view? What is a point of view? This question can now be answered quite easily. A person's world view is his or her image system, the totality of one's spatial, temporal, relational, personal, evaluative images in their interrelations. If our image systems give each of us our world as organized, with meaning and value, then our world view is really our image system. Sometimes point of view means the same as world view. Frequently, to speak of a point of view on some question is to indicate that problem, question, issue, aspect of the world, viewed in the light of some particular interest. Given our discussion of the image system, we may widen this conception. Not only one's interest in the sense of value commitments and emotional attachments, but also the whole system of one's images as they pertain to some question, that aspect or portion of our world view which bears on that issue, determines or constitutes one's point of view on it. 
Our discussion of Lippmann's views on how the stereotypes in our world view are bound up with perception suggests that humans do, in large part, impose interpretations on their world. Humans may experience signs. But what they see, perceive are what their stereotypes tell them these signs signify. As we have pointed out, Lippmann regards persons' experience thus interpreted, or this system of interpretation, as not their environment but a pseudoenvironment. Our discussion of how the image system serves the meaning and egodefensive functions gives further evidence that the image system is a construct. As Katz points out in discussing ego-defensive attitudes, "The objects and situation to which they are attached are merely convenient outlets for their expression... The attitude is not created by the target but by the individual's emotional conflicts. And when no convenient target exists the individual will create one." 36 If it is our deep needs which feed the image system, we should not be surprised if our images tell us more about ourselves than about our environment. If because of some need for meaning or need to protect our self-image or some aspect of the public image, we have pictured the world in some way, that picture will be our picture, our interpretation of the situation. And since this interpretation is fed by subjective needs and built from stereotypes conceived before the experiences they interpret, we should not be surprised to find that it is a distinct mistake, a grievous confusion, to call this interpretation "reality." We shall discuss this explicitly when we take up the issue of why egocentricity is a liability for critical thinking. Our discussion of the image system, then, gives ample evidence that Richard Paul's claim is true, that humans do impose an interpretation on their environments, which it is a mistake to regard as "real."

Can we regard this imposing of an interpretation on our experience as a manifestation of egocentricity? If we each take our image system as "real," are we being egocentric or sociocentric? And if this attitude towards the image system is widespread, pervasive, the norm, does this mean that, as Richard Paul suggests, humans are egocentric (and sociocentric) by nature? To answer this question, we must first determine what "egocentricity" means.

In "Piagetian Insights and Critical Thinking," A.J.A. Binker and Marla Charbonneau offer a definition of "egocentricity" based on the work of the child psychologist, Jean Piaget. According to Binker and Charbonneau, "The defining characteristic of egocentrism is the inability of the individual to see his point of view as a point of view; rather he continually confuses it with reality." ${ }^{37}$ On Piaget's view, a young child is completely egocentric. $\mathrm{He}$ cannot distinguish his own experience from reality, and so the question of there being other points of view than his own does not arise for him. As the child grows, he begins to identify with others. However, this does not so much free him from his egocentrism as transform it into sociocentrism. The interests, desires, beliefs, preconceptions of his immediate group become or are incorporated into his world view. He does not recognize this as a world view, but assumes (naively) that people generally share this point of view. Binker and Charbonneau see this egocentricity manifested in many different ways in the thought processes of the child, and, in each case can identify analogies in adult thinking.

Given this understanding of egocentrism and sociocentrism, the evidence that humans impose interpretations on reality which we have just discussed becomes evidence that humans suffer from egocentricity. Whether it shows or constitutes proper evidence that human beings are egocentric or sociocentric by nature is a further, deep question into which we cannot enter here. What we can say is that the analyses of the image system we have been examining suggest that we have ample evidence that egocentrism and sociocentrism are widespread. 
Is egocentrism a liability for critical thinking? We think our reflections on the image system and its attendant egocentricity and sociocentricity indicate that humans are in a situation they desperately need to transcend, from the point of view of strong sense critical thinking. We want to make this plain. In section one, we sketched certain aims of the critical thinker, as portrayed by various authors. Ennis points out that critical thinkers will respect other points of view, that they will seek to reason, as cogently as possible, even from premises with which they disagree. This is the antithesis of egocentrism. As both Ennis and Siegel point out, critical thinkers want reasons. And by "reasons" surely they must mean more than mere rationalizations. They want reasons which will lay claimsome claim at least-to our rational acceptance. Siegel points out that critical thinkers will assess reasons, and Ennis adds that they will base their conclusions on the weight of evidence. So in seeking reasons, critical thinkers are not concerned with finding their reasons, but finding reasons which will have some probative force, at least for other critical thinkers.

But if we are egocentric, if we impose our images on the world, why should we expect such interpretations to be justified by good reasons? That the human image system is an artifact, that it is not a simple, straightforward reflection of the environment raises the question of how justified we are in accepting its picture of the world. Our considerations of the dynamics of the image system give us ample reason to see that in many cases good reasons need not be forthcoming for accepting the image as "reality." If our image system is fed by subjective needs, the need for meaning and the need for ego-defense, what reason have we to think that the beliefs and attitudes incorporated into these self-serving images are in anyway justified, that we have any good reasons for accepting them? That our stereotypes foster prejudgmental thinkingquite literally prejudiced thinking in the etymological sense of that term-means our judgments will be based on stereotyped expectations, not on evidence. We see what we are set to see, what our stereotypes tell us is there. We can only hope that a judgment which precedes the evidence will be a judgment for which we can give genuine reasons. The resistance of the image system to change further indicates what now is obvious-that we should not expect in general that its representations will be justified by good reasons. By seeking to avoid the impact of incoming messages at variance with the image system, if not to avoid such messages altogether, the image system cuts us off from the evidence on which good reasons are based. It further fosters an attitude of dogmatism directly opposed to the critical spirit. Instead of being moved by the weight of evidence, we are moved by the strength of our needs. Clearly, the image system constitutes a distinct liability for critical thinking.

Does our discussion of the image system suggest ways in which its liabilities may be transcended? First, we should point out that it is the egocentrism associated with our image system, the egocentric identification of our image system with "reality" which must be transcended. Although our image system may pose a distinct liability for critical thinking, we may argue that we cannot do without it. Indeed, Lippmann does just this.

The real environment is altogether too big, too complex, and too fleeting for direct acquaintance. We are not equipped to deal with so much subtlety, so much variety, so many permutations and combinations. And although we have to act in that environment, we have to reconstruct it on a simpler model before we can manage with it. To traverse the world men must have maps of the world. ${ }^{38}$

Again, "But there are uniformities sufficiently accurate, and the need of economizing attention is so inevitable, that the abandonment of all stereotypes for a wholly innocent approach to experience would impoverish human life.'”39 
Rather, we must replace the attitude of egocentric dogmatism and absolutism toward our image system with one of tentatitiveness. This attitude is what the philosopher Brand Blanshard calls the rational temper. It is to regard the image system and its stereotypes as a system of hypotheses, defeasible by future experience. Although with this attitude we may have expectations about how our world will behave, about how it is structured, what sort of persons, places, and things are in it, and what values all these have, expectations which we may not be able to justify fully, we shall still be open to disconfirming experiences, contrary, challenging information. We shall seek to revise and refine our image system in their light. We shall be far more willing to confront and assimilate challenging messages, even if this should mean revising the image system. Instead of demanding that the world agree with our preset ideas, we recognize those ideas for what they are-preset ideas. We may have prejudices, but we shall acknowledge that they are prejudices. We shall seek to be aware of their origin, their genesis, using this as a further antidote to dogmatism. We shall try to determine how faithful our images are to "reality" and to keep mindful of their degree of faithfulness.

In short, we must develop a critical attitude toward the image system. Our image of the image system must not picture it giving absolute or final truth but providing at best a practically or pragmatically useful way of getting around in the world. Lippmann contrasts these two attitudes nicely when he says:

What matters is the character of the stereotypes, and the gullibility with which we employ them. And these in the end depend upon those inclusive patterns which constitute our philosophy of life. If in that philosophy we assume that the world is codified according to a code which we possess, we are likely to make our reports of what is going on describe a world run by our code. But if our philosophy tells us that each man is only a small part of the world, that his intelligence catches at best only phases and aspects in a coarse net of ideas, then, when we use our stereotypes, we tend to know that they are only stereotypes, to hold them lightly, to modify them gladly. ${ }^{40}$

How do our considerations of the image system, its nature, sources, and dynamics, suggest how this critical attitude might be cultivated?

First, just recognizing that we have an image system, that it filters and transforms incoming information about our environment into a constructed picture of the world, and that confusing this picture with the world itself is a distinct liability for critical thinking, should be a first step toward replacing egocentric attachment with a more detached attitude. How can we change our attitude toward our image system, how can we recognize that we have to outgrow egocentrically identifying it with reality unless we are first aware of the problem? We must first recognize that we have this liability for critical thinking before we can deal with it.

Once we recognize this, our account of why egocentric attachment to the image system is a liability for critical thinking should begin to inject a sense of healthy skepticism into our attitude. Recognizing that through preset ideas and resistance to change our image system tends to cut us off from the evidence on which good reasons are based certainly should foster skepticism toward the images of the system. Again, the fact that an image was accepted to satisfy some subjective need should cause us to question the image. In addition to these considerations, the fact that a significant part of our system consists of a stock of images transmitted to us by society, that this is a major source of our images, should further our critical attitude. If society has simply transmitted these images, we most likely have picked them up uncritically. Does the fact that society has transmitted some image constitute a sufficient reason, significantly weighty evidence, to regard that image as so true to reality that it is 
beyond need of any revision?

Recognizing that ego-defensive needs drive the development of the image system should lead to a further step in freeing us from egocentricity. That our image system is fed by such needs suggests that we may grow as critical thinkers by confronting these needs. Surely if our holding certain images is part of our solution to some inner conflict, then we would not expect these images to be given up unless these conflicts were resolved. For example, if maintaining some illusion of power or superiority is necessary to shore up our egos, then we shall not ordinarily abandon such an illusion unless our needs for power and superiority were worked through. If the images were abandoned absent these therapeutic changes, we should expect them to be replaced by other images satisfying these same needs and so accepted just as uncritically. To cease clinging to such images, we need to become strong enough to do without them. But this involves an analytic process of recognizing these needs, the factors that brought them into being, and their consequences for our overall growth as persons, including our growth as critical thinkers. So the Socratic maxim "Know thyself" is crucial for strong sense critical thinking, as it is crucial for wisdom in general. To develop as critical thinkers, we must outgrow these egocentric needs. But conversely, should there be some commitment to critical thinking, and some familiarity with the skills of thinking critically, we should expect that overcoming these ego-defensive needs would advance our development as critical thinkers in the strong sense.

Is confronting, analyzing our egocentric needs an assay in dialectical or dialogical thinking? Can we also say this of recognizing that we have image systems and that they pose liabilities for critical thinking? Is this to adopt some other point of view, or do we rather have additional ways to grow as critical thinkers here? To give an adequate answer, we should have to go into detail about dialectical thinking, and that is beyond our scope in this paper. But we can make this point. To confront our egodefensive needs, to see their origin, current function, and effect, is to take a radically different stance toward these needs than to identify with them. It is to look at these needs with a measure of detachment. Likewise to recognize that we have image systems is to in some sense break our identification with them. We may not be adopting a viewpoint determined by a competing need or interest, it is not clear that this is to adopt a competing world view, but it does mean that we shall be looking at these needs and images of ours from a radically different angle. Whether this should count as dialectical thinking depends upon further articulation of what dialectical thinking is. What we can say is that our reflections on the image system and its connection with critical thinking have shown that self-knowledge is a way, and a necessary way, of growing as a critical thinker.

So far, we have discussed how awareness of the image system and its dynamics can lead to changes in our attitude toward our own image system. It can also lead to greater ability to enter into someone else's point of view. It gives us further specific questions for engaging in dialectical or multi-logical thinking. Besides asking what rival, competing interests others might have in a given situation and how this might give rise to alternative points of view, we might ask what images others entertain, how are they trying to make meaning, deal with conflicts.

Not only can we use such considerations to evaluate the strength of our claims in the light of rival points of view, we can use such considerations to make ourselves more open to others and their points of view. Suppose certain statements, arguments, behavior seem inexplicable, if not outrageous, to us. If we are aware of the image system and its all important role in shaping one's picture of the environment-in creating a pseudo-environment, to use Lippmann's 
term again-which determines how persons react, then we shall have a series of considerations which may help us explain this behavior. At least, these considerations should indicate where to look for such an explanation. Consider, for example, the anti-American pronouncements of radical Moslem fundamentalists, or the Soviet Union's shooting down of Korean Air Lines Flight 007 on September 1, 1983. In the light of our discussion, can we simply dismiss these Moslem fundamentalists as crazy and the Soviets as evil? We can rather ask-What image do these Moslem fundamentalists have of the West and of the United States in particular? What stereotypes have formed that image? What needs does it satisfy? Again, KAL Flight 007 invaded Soviet air space. That much is fact. What did this mean to the Soviets? What did their images, stereotypes, preconceptions bring to their perception of this event? From their point of view, i.e. from the perspective of their image system, was their shooting down of this plane an act of moral turpitude? Clearly, this is reasoning from the Moslem fundamentalist or Soviet point of view.

This is not to say that such dialectical reasoning will convince us that all such behavior is acceptable. Even when we reason from someone's point of view, even allowing that point of view to be viable, his or her claims or behavior may not be justifiable. Certain behavior may be wrong, even from someone's point of view. We may also find that although what someone has said or done seems perfectly appropriate from his or her point of view, that point of view is mistaken. Here again, we may not find the behavior acceptable, but will we judge the person to be evil, stupid, depraved? Will we not rather admit that here an element of human tragedy enters the situation? Morally appraising such situations is of course complex. But our consideration of the image system suggests how issues of judging others must be tempered by considerations of how they perceive their ac- tions. Lippman points out that overcoming our egocentric attachment to our image system is a prerequisite for taking this more tolerant attitude. Without it, we cannot conceive that someone else perceives and bases his behavior on a different set of facts, and that this explains why he is "different."

\footnotetext{
Such an explanation we avoid, because it saps the very foundation of our own assurance that we have seen life steadily and seen it whole. It is only when we are in the habit of recognizing our opinions as a partial experience seen through our stereotypes that we become truly tolerant of an opponent. Without that habit, we believe in the absolutism of our own vision, and consequently in the treacherous character of all opposition. ${ }^{41}$
}

Hence consideration of the image system not only helps us reason dialectically, it lets us be more human. By asking questions about the images of others, we seek to foster human understanding, even if those whose ways seem strange, threatening, well nigh abhorrent. By overcoming our egocentricity, we shall regard fewer persons as "the enemy."

The possibility of transcending our egocentricity and sociocentricity through appreciation of the image system raises some significant issues for teaching critical thinking in the strong sense. How can educators incorporate these insights into teaching critical thinking?

\section{Pedagogical Considerations}

The central pedagogical problem that has emerged from our discussion is how do we help students overcome their egocentricity and sociocentricity or, what is the other side of the same coin, how do we foster the rational temper, the tentative attitude to our image system? ${ }^{42}$ Our discussion in the previous section contains certain proposals for advancing this goal. The first is simply making study of the image system and its stereotypes part of the critical 
thinking curriculum. To become critical thinkers, we need to become aware of the image system about which we are trying to cultivate this tentative, open attitude. This means being aware of our stereotypes as stereotypes, indeed becoming aware that our thinking is permeated by principles of interpretation and evaluation which we have made ourselves and imposed on experience, and which are subject to critical scrutiny.

Once we recognize our stereotypes, we may foster the critical attitude toward them by considering their origin and justification. We have already developed this point to a great extent in the last section. If an image is the outgrowth of subjective needs, why should it give us a justifiable picture of the world, one we can claim with rational force should be accepted by others? Although some images are based on personal experience, how wide is a person's experience? Surely, by nature, it is limited. Do we know even our intimate acquaintances through and through? Do we know even ourselves? Can we say with any confidence that we have taken all the relevant facts into account when fixing some image? Surely awareness of our limitations as humans should foster tentativeness towards our stereotypes. This should only be heightened by recognizing that our stereotypes further limit our awareness by creating blind spots, by leading us to register only what conforms to our image system. We can similarly question the justification of stereotypes inherited from our culture. Why should our culture give us a justified picture of the world? What was the origin of these images? How limited was the experience they were based on? What sociocentric needs, what societal bias do they serve? Is this their fundamental source?

In this connection, the study of stereotypes prevalent in other cultures or at other historical times might be quite appropriate. Studying how we are prejudiced might at first be too close for comfort. Studying how someone else was prejudiced may be sufficiently removed from our per- sonal core and its subjective needs to permit objective study. This may be, if the situation studied is not too obviously analogous to our own. In particular, studying how propagandists build up image systems by exploiting latent conditions in the audience, including ego-defensive needs and needs for knowledge-and there is a vast amount of material here intimately related to the themes of strong sense critical thinking-may give us insight into the origin and development of stereotypes, and may make more trenchant the question of their rational justification. But ultimately, such study should throw some light onto the development of our own image systems and cast doubt on their absolute reliability.

It should throw some light-but again, because of our resistances, it may not. We may be able to see how the other fellow is prejudiced, how he should take a more humble attitude towards his image system, but our stereotypes remain unassailed. Indeed, we may be left feeling even more superior, for now we have an explanation for the other person's irrationality without registering how that explanation applies to our own. ${ }^{43}$ Our stereotypes remain unassailed. They remain unassailed because the subjective needs which fed their development and maintain their strength have not been touched. How can we have an attitude of tentativeness to our image system, to our stereotypes, if they are heavily invested in serving powerful subjective needs, especially ego-defensive needs?

This brings us to our central pedagogical question. How can this freedom be fostered in the classroom? Indeed can such liberation be fostered there? Is there something fundamentally wrong headed in thinking we might do this as classroom teachers? Is this change a matter of therapy rather than formal education? This is a deep question which ultimately cannot be answered without a theory, an account of what this liberation means. What we can only hope to do here is highlight the difficulty of the issue and suggest how we might meet this 
challenge in the classroom. The difficulty is that we are talking about something which goes to the core of each student's personality, and are seeking to bring about personal change. Is there thus a therapeutic aspect to developing as a critical thinker and is it dangerous to proceed without therapeutic competence and therapeutic sensitivity?

I think there is this therapeutic aspect. But I also think critical thinking instructors can gain important clues from the writings of psychologists on how to proceed here. In particular, material on how attitudes and stereotypes serving the knowledge and egodefensive functions are changed is quite relevant. Factors of our image system which serve the knowledge function are modified when they no longer adequately supply meaning, when a person is aware of a sufficient number of facts which they do not explain, with which they are inconsistent ${ }^{44}$ Can we, as critical thinking instructors, present information at odds with any prevalent stereotypes, the very sort of information which would cause their revision? If we can, then wouldn't this be a powerful illustration of why the image system must be open to modification?

The real challenge, I believe, comes with changing attitudes and stereotypes serving the ego-defensive function. This may well cause the most difficult intransigence to deal with. Yet we can have change even here. Katz points out that egodefensive attitudes may possibly be changed with insight into the mechanisms of defense. "Information about [a person's] functioning may have an influence, if presented without threat, and if the defenses do not go too deep into the personality..."45 As critical thinking instructors we are developing these insights through making our students aware of stereotypes and their defensive role. Making students aware of the whole structure and dynamics of the image system, especially developing its dynamic of serving egocentric needs, fosters these insights. Our reflections in this paper, then, have very direct practical implications for teaching critical thinking in the strong sense, and for what should be taught.

\section{Philosophical Considerations}

Our discussion of how egocentricity is a liability for critical thinkers in section four has made one philosophically controversial presupposition. We have said that critical thinkers want good reasons, i.e. reasons which will lay claim to rational acceptance. We have also developed in both sections four and five how the image system poses a threat to critical thinking in that it fosters making judgments based on stereotypes, satisfying some internal need, rather than making judgments based on good reasons. The presupposition here is that some reasons are objectively good reasons. Such reasons are not merely good from some perspective or in accordance with some world view. Rather such reasons have an epistemic, normative force. Anyone who entertains them as a rational discussant should appreciate this force. We should be able to justify that they are good reasons by appealing to criteria which should be accepted by any genuine participant in the discussion.

We should emphasize that when we speak of good reasons here, we mean "good" in the sense of "logically cogent." Rhetoricians, in appraising arguments, distinguish various standards, including the effect standard and the validity standard. ${ }^{46}$ Effect deals with the persuasive force of arguments. Validity incorporates issues of logical cogency. Now if from the point of view of effect, a good argument or a good reason is one which moves, persuades the audience to accept the conclusion, there is no doubt that what will be a good reason for one audience will not be good for another. What will move one audience to accept a conclusion may have exactly the opposite effect on another, or leave that audience unmoved. Persuasive force is au- 
dience relative. But that is not the sense of "good" in which we speak of good reasons. Good reasons are good because they are logically cogent-they give us reason to accept some conclusion which has logical and epistemic force, and this force, we presuppose, is not relative to audience or individual, but objective.

But can we simply presuppose this? Surely of the many forms of relativism, ${ }^{47}$ there is one which denies just this-that we can objectively evaluate reasons. Such a relativist can even use our terminology to formulate his or her challenge. There is no such thing as an objectively good reasonthere are just images of good reasons. What criteria a person might offer for good reasons are simply articulations of his image of a good reason. We simply have images of good reasons, nothing more. True, the images of many persons may converge on what they regard as the central characteristics of a good reason. We may have a public image of a good reason, but it is an image nonetheless. If someone does not agree with us that a reason is good-or bad, and the disagreement is not the product of some confusion, then we can only say that he has a different image of what a good reason is, not that he is wrong epistemically. Reasons are not good; they are just good for certain persons, meaning that they are in accord with the criteria constituting their image of a good reason.

Such a relativist position is endorsed by Hartry Field in [1982]. Field points out that a relativism with respect to values does not entail a relativism with respect to truth. One can hold that statements are true or false simpliciter, not true or false for some person, while holding that values, including such epistemological values as being justified, are relative. For Field, epistemological relativism is

the doctrine that the basic epistemological properties are not such properties as that of belief $B$ being justified, but rather such relativized properties as that of belief $B$ being justified relative to evidential system $E$.
(An evidential system is, roughly, a bunch of rules for determining under what conditions one is to believe various things; a belief is justified relative to an evidential system in certain circumstances if the rules license the belief under those circumstances. $)^{48}$

The epistemological relativist cannot admit that among the values $E$ ranges over is the true evidential system, that a belief may be justified relative to this system. "For that would amount to saying that the belief is justified relative to that evidential system which declares a belief justified just in case it is justified; and since the last use of the term 'justified' is unrelativized, the epistemological relativist cannot say this." 49 "Being justified" 'must always be relativized. What the epistemological relativist can do is to talk about factual properties of evidential systems. The reliability of an evidential system, its tending to lead to a certain proportion of truth over falsity, is a factual property of the system. So the epistemological relativist can say not only that belief $B$ is justified relative to some system $E$, but can also say that $B$ is justified relative to a highly reliable system $E^{*}$. In saying this, he gives $B$ " epistemological praise" 50 just in case he values reliability. He need not say that all evidential systems are equally good. Some are better than others. One system is better than another just in case it better serves or preserves his values. One might hold all sorts of values vis-a-vis evidential systems. Besides reliability, someone may also value the power of an evidential system, how much the system allows us to believe. An evidential system which licensed us to believe only tautologies would be highly reliable but have little power. How do we trade off power and reliability? Different believers will do it differently and so there will be different evidential systems. "There is no 'correct' set of goals or 'correct' trade-off formula among them." ${ }_{51}$ And so there is no "correct" evidential system, a system which would certify certain reasons as being genuinely good simpliciter. 
What may we say to this relativist? The first thing to admit is that we have this profound disagreement with him. We are using "good reasons" in a non-relativist sense, and understand them to be good objectively or absolutely. And we believe such antirelativism is shared by many in the critical thinking movement. Witness first of all the quotes from Ennis and Siegel about the goals of a critical thinking education which begin section one. In books and papers, most notably in Relativism Refuted, Siegel has attacked a great variety of relativist positions. When informal logicians present such criteria for logical cogency as acceptability of the premises, their relevance to the conclusion, and their supporting it with adequate weight, ${ }^{52}$ they intend these to be genuine criteria for good arguments and so good reasons. They are not simply articulating their evidential system. Hence, we see this philosophical stance as not unique to us, but one receiving significant support in the critical thinking movement.

What can we say in reply to the epistemological relativist? We should first note that Field's object in [1982] is not to argue for epistemological relativism, but simply to articulate his view and to argue for its viability, "to make believable that it is a coherent and platable doctrine." ${ }_{53}$ Now epistemological relativism is not the received philosophical view, supported by a wide consensus in the philosophical community, the way a Kuhnian paradigm might be received in some scientific community. It is not part of philosophical common knowledge, nor is it self-evident. Nor can we "see" it in some other immediate way. Hence, we cannot say that there is a presumption for it, but rather that the burden of proof rests with the relativist to argue for his view.

But it is precisely here that the relativist comes into significant difficulty. Should he accept the challenge and take up the burden of proof, on his own grounds he must first answer this question: With respect to whose evidential system will I justify epistem- ological relativism-my own or my challengers'? If my challengers are antirelativists, is it likely that I can justify my relativism with respect to their evidential system? If my challengers are agnostic on the issue of epistemological relativism, again how likely is my justifying relativism on their system? Unless I know what my challengers' evidential system is, these questions are posed so abstractly as to be impossible of answering. But do I know what my challengers' evidential system $E$ ' is, as opposed to my system $E$ ? Is my best bet simply to argue for epistemological relativism by putting forth reasons good according to my evidential system $E$ and hoping $E$ is sufficiently congruent with $E^{\prime}$ that my challengers will accept my reasons as good reasons also?

Let's assume the relativist takes this tack. Let's suppose he can produce a good case for his relativism from the point of view of $E$ but not $E^{\prime}$. His reasons are not counted good reasons by his challengers. Can he accept a burden of proof to show that $E$ ' should be modified in the direction of $E$, to make it more congruent with $E$ ? But then what evidential system should he adopt as a standard for this argument? It looks like we are at the beginning of an infinite regress here. Or are evidential systems beyond justification? Can we take up no challenges to our system? It is precisely here that we make contact with Siegel's critique of Field's position in [1987]. Siegel says

The obvious question to be put to Field's brand of relativism is: can rival, incompatible evidential systems themselves be nonrelatively or objectively or rationally evaluated?... If rival, incompatible $E$ 's cannot be non-relatively evaluated, then it is difficult to see how any belief, no matter how bizarre, can be ruled out or evaluated negatively, for some $E$ which will sanction it could always be constructed... The notion of epistemic justification will be not simply relativized, but trivialized; to say that a belief is justified will be not to praise it at all. ${ }^{54}$

But it is Field's very position that rival, incompatible $E$ 's can only be relatively 
evaluated. True, it is open to the relativist on Field's account to say that one system is more reliable than another or more powerful than another, or has a different trade off between reliability and power than another. It is also open to the relativist to say that because of this, one system is better than another. But-in Field's own words - "the evaluation of one evidential system as better than another is dependent on what characteristics we value in evidential systems, and different people may differ considerably in the characteristics they value." 55 So when a consistent relativist on Field's view says that one evidential system is better than another, he means only better in realizing his values, "better in achieving certain goals... and there is no 'correct' set of goals or 'correct' trade-off formula among them." 56

If two relativists disagree on their epistemic goals, we should expect them to accept different evidential systems. Even if they agree on their epistemic goals, relativists might not accept the same evidential system. For to justify the claim that one evidential system better serves some epistemic value or goal than another, we must appeal to evidence, and such an appeal presupposes an evidential system. So if two relativists agreed on their epistemic goals but disagreed on their current evidential systems, their evaluations of those systems (or of any others they might consider) could be distinctly different.

The upshot of these considerations is to see that Field's epistemological relativism ultimately renders rational discussants dialectically impotent, ${ }^{57}$ at least in many of the possible situations they might enter. If two persons are to settle some disagreement of opinion by an argumentative interchange, trying to get at the truth by a series of challenge and response exchanges, then there must be agreement in particular on what challenges and what responses advance the interchange toward its goal. That is, there must be agreement on an evidential system. Now one can imagine that the participants could simply adopt a common evidential system for the sake of furthering the discussion. But such a move is counter to the spirit of dialectic, where the participants are genuinely seeking to resolve a dispute. Would seeing that a claim were justified on the basis of certain evidence with respect to an evidential system one did not accept constitute much reason to accept that claim? Would seeing this provide a resolution of the question at issue? But Field's view leaves it quite open that disagreements of opinion could arise between persons with wildly differing epistemic values and wildly differing evidential systems. How could they enter into dialogue with one another in any genuine, non-artificial sense?

Field might want to argue that this exaggerates the potential differences between rational participants in a dialogue. For he holds that there are "intuitively desirable goals that we would like our evidential systems to satisfy," 58 that among them presumably is reliability. ${ }^{59}$ If this be the case, then there might not be as much variety in actually held evidential systems as is logically possible. Participants in a rational discussion will presumably subscribe to certain of these intuitively desirable goals. Given this, resolution of disagreements might be more tractable than one would at first think. But talk about intuitively desirable goals is very problematic on Field's view. On what are these intuitions based? Is there anything epistemically normative in these intuitions? Are they simply a matter of taste? It is hard to see how one could regard them as normative and still be a strict relativist. If there is something normative in these intuitions, then we do have some epistemic standards independent of particular evidential systems. But if they are not normative, then is it not possible for someone simply to dismiss them as his epistemic goals? And so it is quite possible that epistemic goals and evidential systems can vary in the extreme. But if this be so, can there be genuine argumentative 
interchange between persons holding such differing goals and evidential systems? Can one person genuinely attempt to rationally convince another of the rightness of his view? If epistemic goals and evidential systems differ widely enough, then over a range of questions at least there can be no rationally resolvable agreement.

We can give a very concrete example of this problem. Above we alleged that the burden of proof was on the epistemological relativist to argue for his relativism. But we could imagine an epistemological relativist refusing to admit that the burden of proof was on him to justify, argue for epistemological relativism. For according to his evidential system, epistemological relativism needs no defense. His evidential system simply includes a principle specially certifying that epistemological relativism carries an undefeated presumption. According to his system, epistemological relativism is as sure as self-evident, in effect a basic axiom. Hence, he will not argue for his view because there is no need to argue for it on his evidential system, although he concedes that others will take a different view of the matter. But he can only genuinely argue from his own pespective, not theirs. And so he is apparently incapable of entering into any genuine dialogue to resolve this disagreement over relativism.

This reiterates that epistemological relativism leads to dialectical impotence. Epistemological relativism leads to the position that where evidential systems differ, one may very well be incapable of convincing others, of genuinely entering into dialogue with them. Is this not too high a price for relativism? We thus have a reply to those who would fault our account of the liabilities the image system poses for critical thinking. Our account does make a philosophically debatable presupposition, that there are good reasons. But we are not ashamed to claim that there are genuinely good reasons, reasons which are epistemically normative. The epistemological relativist alternative leads to dialectical impotence.

\section{Summation}

We have now shown the importance of the human image system for the enterprise of thinking critically in the strong sense. Our account of the image system suggests that the natural human condition contains serious liabilities for critical thinking. One does not simply receive messages from the world, but messages which are filtered through an image system. This system serves egocentric needs and predisposes us to make prejudiced, uncritical judgments. However, there is reason to believe that this situation can be transcended through insight into the image system and its growth and dynamics. It is for these reasons that I commend studying the image system to those interested in strong sense critical thinking. By developing and further understanding these issues, in particular how the image system can be apprehended and insight into its dynamics promoted, we may make a contribution to developing critical thinking in the strong sense.

\section{Notes}

1 The original version of this paper was prepared for The Fourth International Conference on Critical Thinking and Educational Reform, Center for Critical Thinking and Moral Critique, Sonoma State University, Rohnert Park, California, August 1986. We wish to thank an anonymous referee of Informal Logic for a number of valuable suggestions for strengthening this paper significantly.

2 Ennis, [1988], p. 1.

3 Siegel, [1985], p. 11.

4 Siegel, [1985], p. 11. 
5 This is as Prof. Siegel has amplified these ideas in [1988]. He also expresses this view in [1980], p. 9.

6 To the best of my knowledge, Paul introduced this concept of "critical thinking in the strong sense" in [1982]. He has developed the notion in numerous further papers. See [1985], [1987]. Paul presents a bibliography of previous work in [1987].

William Maker, working apparently independently of Paul, has presented a very similar view of critical thinking in [1982]. Maker sees the informal logic course as a uniquely apposite way of advancing certain central objectives of teaching philosophy: "intellectual liberation," "the emancipation of thought from authoritarianism, unreflective orthodoxy and intolerance," training students "to recognize how assumptions, beliefs and prejudices... guide and shape our thinking, our attitudes, and the ways in which we relate to the world, ourselves and to other individuals." ([1982], p. 18) Over against this "natual" mode of thinking, the informal logic course can present criteria of rationality which seek to foster and are justified by fostering freedom from "confusion, distortion, one-sidedness and aperspectivism." ([1982], p. 18) Aperspectivism, what Paul means by egocentricity, is at basic enmity with the free, liberated thought Maker wants to foster. Aperspectivism takes its own viewpoint as self-evidently correct, refuses to accord any respect to differing points of view, and is ignorant of the need to justify viewpoints and of their conditioning by various social and personal forces. One's perspective is not just a perspective but the way things really are, and no one else has any right to differ from it. The goal of the informal logic course, as of philosophical instruction and liberal arts education in general, is "intellectual emancipation from aperspectivism through critical and mutually constituted communicative understanding." ([1982], p. 19)

7 Paul, [1982], p. 4.

8 Paul, [1985], p. 11.

9 Paul, [1982], p. 5.

10 The first two sections of Stephen Toulmin's essay, "The Layout of Arguments,"' included in The Uses of Argument, [1958], give significant insight into the structure of dialectical thinking. For our application and development of these notions, see [1985] and [19_].
11 See Boulding, [1956], especially Chapters I, IV, $\mathrm{V}$, and XI.

12 See Clevenger, [1966], Chapter Five, and Sproule, [1980], Chapter 7, especially pp. 221-44. Although Clevenger discusses images, he does not mention Boulding by name.

13 See Lippmann, [1922], especially Parts I and III.

14 Boulding, [1956], pp. 47-48.

15 Boulding distinguishes certain other aspects of the image system which, for our purposes here, we need not discuss. See [1956], pp. $48 \mathrm{ff}$.

16 Clevenger, [1966], p. 82

17 See Clevenger, [1966], pp. 82-83.

18 Clevenger, [1966], p. 83

19 Sproule, [1980], pp. 222-25.

20 Lippmann, [1922], p. 7.

21 Lippmann, [1922], pp. 10-11.

22 Lippmann, [1922], p. 81.

${ }^{23}$ Lippmann, [1922], p. 88, 89.

24 Lippmann, [1922], pp. 81-82.

25 See Sproule, [1980], pp. 221-22.

26 Boulding, [1956], p. 6. By using the word "knowledge," Boulding does not mean to claim that the elements of each person's image are true or veridical representations of the world. Rather, they are what is believed true.

27 Boulding, [1956], p. 64

28 Compare Katz, [1960]. See p. 21 of reprint

29 Lippmann, [1922], p. 96.

30 Clevenger, [1966], p. 90.

31 See Clevenger, [1966], p. 91

32 This illustrates the four types of selectivity fostered by the image system identified by Sproule in [1980], pp. 237-40: selective exposure, selective recall, selective attention, and selective interpretation.

33 Lippmann, [1922], p. 110.

34 Lippmann, [1922], p. 95.

35 For a discussion of how messages affect images, see Boulding, [1956], pp. 7-12, and Clevenger, [1966], pp. 93-98.

36 Katz, [1960], in Beisecker and Parson, [1972], p. 23. 
37 Binker and Charbonneau, [1983], p. 12.

38 Lippmann, [1922], p. 16.

39 Lippman, [1922], p. 90.

40 Lippmann, [1922], pp. 90-91.

41 Lippmann, [1922], p. 126.

42 The problem of dealing with egocentricity has already been addressed by Binker and Charbonneau in [1983]. Their discussion contains at least one specific proposal for dealing with egocentricity which could be applied in accomplishing one of the pedagogical goals outlined in this section. We argue that just recognizing that we have an image system can be a way of loosening its hold. Binker and Charbonneau point out that some images involve associations. Advertisers build images by building associations-coffees, gasolines, furniture are all given "personalities." We can identify these images by thinking of associations we and others make, and can begin to dissolve their power by considering whether judgments based on these associations are justified.

Harry P. Reeder in [1984] also addresses dealing with egocentricity and sociocentricity, indicating how certain rhetorical strategies can be helpful in opening the audience to considering other points of view.

43 We wish to thank the anonymous referee of Informal Logic for this point in particular.

44 See Katz, [1960], p. 31.

45 Katz, [1960], p. 29.
46 See Sproule, [1980], pp. 74-92 for a discussion of the various standards for criticizing arguments.

47 In [1987], Harvey Siegel discusses many forms of epistemological relativism and indicates other types such as ethical. We shall make contact with Siegel's critique of this form of relativism shortly.

48 Field, [1982], p. 563.

49 Field, [1982], p. 563.

50 Field, [1982], p. 564.

51 Field, [1982], p. 566.

52 These criteria are endorsed in texts by Govier [1985], Johnson and Blair [1977], and myself [1988]. At Conference 88 on Critical Thinking, Christopher Newport College, Newport News, VA, I sensed a growing consensus on these three criteria.

53 Field, [1982], p. 562.

54 Siegel, [1987], pp. 26, 27.

55 Field, [1982], p. 565.

56 Field, [1982], p. 566.

57 Compare Siegel, [1987], pp. 20-21 for a discussion of the impotence of relativism.

58 Field, [1982], p. 566.

59 Field, [1982], p. 564. “An epistemological relativist can want, and presumably will want, to bring his belief-forming behavior into accordance with some reliable evidential system."

\section{References}

Beisecker, Thomas D. and Parson, Donn W., eds [1972]. The Process of Social Influence: Readings in Persuasion. Englewood Cliffs, NJ: Prentice-Hall.

Binker, A.J.A. and Charbonneau, Marla. [1983]. Piagetian Insights and Teaching Critical Thinking. Informal Logic Newsletter 5,2: 10-15.

Boulding, Kenneth E. [1956]. The Image: Knowledge in Life and Society. Ann Arbor, MI: The University of Michigan Press.

Clevenger, Theodore Jr. [1966]. Audience Analysis. Indianapolis, IN: The Bobbs-Merrill Company, Inc.
Ennis, Robert H. [1988]. Goals for a Critical Thinking/Reasoning Curriculum. Unpublished statement prepared for Conference 88 on Critical Thinking, Center for Critical Thinking, Christopher Newport College, Newport News, VA.

Field, Hartry. [1982]. Realism and Relativism. Journal of Philosophy 79: 553-67.

Freeman, James B. [1985]. Dialectical Situations and Argument Analysis. Informal Logic 7, 2\&3: $151-62$.

[1988]. Thinking Logically: Basic Concepts for Reasoning. Englewood Cliffs, NJ: Prentice Hall. 
[19_]. Dialectics and the Macrostructure of Arguments. Dordrecht-Holland/ Providence, R.I.-U.S.A.: Foris Publications.

Govier, Trudy. [1985]. A Practical Study of Argument. Belmont, CA: Wadsworth Publishing Company.

Johnson, Ralph H. and Blair, J. Anthony. [1977]. Logical Self Defense. Toronto, Canada: McGraw-Hill Ryerson.

Katz, Daniel. [1960]. The Functional Approach to the Study of Attitudes. Public Opinion Quarterly 24: 163-204. Reprinted in Beisecker and Parson, eds. [1972].

Lippman, Walter. [1922]. Public Opinion. New York, NY: The Macmillan Company.

Maker, William. [1982]. Teaching Informal Logic as an Emancipatory Activity. Informal Logic Newsletter 5, 1: 17-20.

Paul, Richard. [1982]. Teaching Critical Thinking in the "Strong" Sense: A Focus on SelfDeception, World Views, and A Dialectical Mode of Analysis. Informal Logic Newsletter 4,2: 2-7.

, [1985]. Background Logic, Critical Thinking, and Irrational Language Games. Informal Logic 7,1: 9-18.

. [1987]. Critical Thinking and the Critical Person. Thinking: The Second International Conference, D.N. Perkins, John Bishop, and Jack Lochhead, eds. Hillsdale, N.J.: Lawrence Erlbaum Associates, Inc.
Reeder, Harry P. [1984]. The Nature of Critical Thinking. Informal Logic 6,2: 17-20.

Siegel, Harvey. [1980]. Critical Thinking as an Educational Ideal. The Educational Forum November 1980: 7-23.

[1985]. Educating Reason: Critical Thinking, Informal Logic and the Philosophy of Education-Part One: A Critique of McPeck and a Sketch of an Alternative View. APA Newsletter on the Teaching of Philosophy Spring-Summer 1985: 10-13.

[1987]. Relativism Refuted: A Critique of Contemporary Epistemological Relativism. Dordrecht-Holland: D. Reidel Publishing Company.

[1988]. Educating Reason: Rationality, Critical Thinking and Education. New York, NY: Routledge.

Sproule, J. Michael. [1980]. Argument: Language and Its Influence. New York, NY: McGrawHill Book Company.

Toulmin, Stephen. [1958]. The Uses of Argument. Cambridge: Cambridge University Press.

JAMES B. FREEMAN DEPARTMENT OF PHILOSOPHY HUNTER COLLEGE, CUNY

695 PARK AVE.

NEW YORK, NY 10021 